NEWS

\title{
Freedom of spill research threatened
}

\section{Scientists call for impartial funding and open data as BP and government agencies contract researchers.}

It started with a story in the Press-Register of Mobile, Alabama. On 16 July, the paper reported that beleaguered oil giant BP was hurriedly signing up scientists to gather data for the company, to aid its defence in cases arising from the Deepwater Horizon spill. The catch was that these lucrative contracts also restricted the scientists' freedom to publish their research. Within a week, headlines around the world were accusing BP of 'gagging' scientists.

But researchers in the Gulf of Mexico region describe a more complex situation. Scientists, they say, are being trapped in the middle of a scramble by BP and the federal government to round up expert witnesses. The rush is being driven by the Natural Resource Damage Assessment (NRDA), a process defined by US federal law, in which those responsible for the spill, along with state and federal agencies, collect data to assess the environmental impact of the accident. Government agencies typically rely on their own scientists, whereas responsible parties consult with firms that have in-house scientific expertise, says Michael Wascom, a coastal and ocean management lawyer at Louisiana State University (LSU) in Baton Rouge. The size of this spill is unprecedented, however, so academic scientists are increasingly being called on.

Because the NRDA is part of a legal process, the scientists' results are unavailable for public review. "When you collect data for the [NRDA] and agree to analyse them, you are essentially foreclosing on your ability to publish those data because

"We are more than happy to work with BP or with anybody else, but it's going to be with full academic freedoms." they're going to be involved in court cases and they're subject to all kinds of sequestering and gag orders," says Ian MacDonald, an oceanographer at Florida State University in Tallahassee.

Some universities have bridled at the restrictions. In early June, lawyers representing BP contacted the University of South Alabama in Mobile, asking to set up contracts with scientists in the Department of Marine Sciences. According to Russ Lea, the university's vice-president for research, the terms that BP suggested sounded "very unfavourable and very non-transparent" regarding academic freedoms. Data collected by scientists under contract would be confidential, and could not be published for three years, says Lea. "Our rejoinder was that we are more than happy to work with BP or with anybody else, but it's going to be with full academic freedoms," he

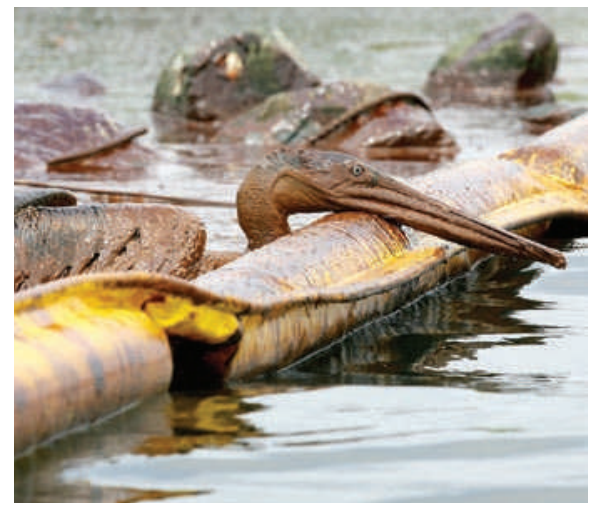

Wildlife are suffering in the Gulf of Mexico.

says. They never heard from BP's lawyers again. Yet Lea adds that BP's desire to hire experts is not particularly egregious - it can happen in any big lawsuit.

The National Oceanic and Atmospheric Administration (NOAA) has a similar position on its NRDA contracts. "We will not hire anyone who refuses to sign a confidentiality agreement and could jeopardize the NRDA process," says spokesperson Rachel Wilhelm. But she adds that on 8 July, NOAA decided to waive parts of the agreements and allow scientists to publish their data. "Releasing NRDA 'Preassessment' science data is rarely done in the NRDA process, but it was decided in the interest of transparency, and because of the heightened interest in this particular spill, that this information would be made public," says Wilhelm.

BP lawyers had also approached the Gulf Coast Research Lab in Ocean Springs, part of the University of Southern Mississippi, about contracting the entire lab. When the lab's administration declined, BP sought out individual researchers there, including Joe Griffitt, an aquatic toxicologist. Griffitt says he was among about half a dozen faculty members who signed a BP contract to assess damages and design their spill-response plan. "We thought we could do some good by making sure they had good science underpinning their plan," he says.

Griffitt says that the researchers specifically stated in their contracts that they would not accept any restrictions on publishing research related to the spill. But after a few days of reflection and further discussion with BP's lawyers, they became aware that consulting for BP would bar them from working with federal agencies under the NRDA process, raising concerns that they might be prevented from applying for federal funding altogether. The researchers then unanimously resigned from their contracts, says Griffitt.

BP spokesman Mark Salt says that the company has contracts with "more than a dozen" researchers with expertise in the region, and that it has asked them to "treat information from BP counsel as confidential". But, says Salt, "BP does not take the position that environmental data are confidential. Moreover, BP does not restrict academics speaking about scientific data." However, Salt admits that "a few of the contracts between our local counsel and local university experts contain a three-year restriction on publication. It is BP Legal's intent to remove those restrictions, so that all university and college experts are hired on the same terms."

\section{The cost of openness}

Several scientists contacted by Nature say the episode highlights the lack of spill-research funding that is independent of the NRDA. "We need to get information debated within the scientific literature," says MacDonald.

BP has pledged US $\$ 500$ million in research funding through its Gulf of Mexico Research Initiative; $\$ 30$ million of this has already been split between several Gulf Coast institutions, and is not tied to the NRDA. The National Science Foundation has provided more than $\$ 3$ million in rapid-response funds for oil-spill research, and the Louisiana Sea Grant, administered by NOAA, has offered $\$ 100,000$. But these sums are not enough to match the scale of the problem, experts say. Operating a ship with a robotic vehicle costs about $\$ 50,000$ per day, says Robert Carney, a biological oceanographer at LSU.

"We need a federal source of funding very badly that does not have anything to do with the NRDA settlement," adds Chris D'Elia, dean of the School of the Coast and Environment at LSU. "The federal government is abdicating what I think is a critical role to provide opportunity for funding impartial, peer-reviewed research." Wilhelm says that NOAA is currently reviewing the issue of long-term funding for spill studies, and evaluating "what else is needed to obtain a more thorough scientific understanding of the damage to the Gulf".

Amanda Mascarelli

See also nature.com/oilspill 